\title{
The Seasonal Frequency of Viruses Associated With Upper Respiratory Tract Infections in Children
}

\author{
Hushang Gorjipour ${ }^{1}$, Abdollah Karimi ${ }^{*}{ }^{*}$, Alireza Fahimzad ${ }^{1}$, Farideh Shiva ${ }^{1}$, Fatemeh Fallah ${ }^{1}$, \\ Ahmad Reza Shamshiri ${ }^{2}$ \\ ${ }^{1}$ Pediatric Infections Research Center, Mofid Children Hospital, Shahid Beheshti University of Medical Sciences, Tehran, IR Iran \\ ${ }^{2}$ Department of Epidemiology and Biostatistics, School of Public Health, Tehran University of Medical Sciences, Tehran, IR Iran
}

\section{A R T I C L E I N F O}

Article type:

Original Article

Article history:

Received:18 Apr 2012

Revised: 17 July 2012

Accepted: 07 Aug 2012

Keywords:

Epidemiology

Child

Viruses

Respiratory Tract Infection

Polymerase Chain Reaction

\begin{abstract}
A B S T R A C T
Background: Upper respiratory tract infections (URTI) in children are the most frequent reasons for visiting a family doctor, commonly resulting in inappropriate prescription of antibiotics. In underdeveloped countries, a viral respiratory tract infection may be followed by serious complications. More than 200 viral species are associated with respiratory tract diseases in humans and this number is increasing.

Objectives: This study was carried out to determine the distribution of common viruses responsible for clinical manifestations of upper respiratory tract infections (URTI) in children throughout the 4 seasons of year.

Patients and Methods: This cross-sectional study was performed from October 2009 to September 2010 on 2- month and 12- year -old children with clinical manifestations of acute upper respiratory tract infections referring to the outpatient clinics of a children's hospital affiliated to Shahid Beheshti University of Medical Sciences in Tehran, Iran. Nasopharyngeal samples were collected and tested for Influenza virus, Parainfluenza, Adenovirus, Respiratory syncytial virus (RSV), Rhinovirus and Enterovirus, by polymerase chain reaction (PCR).

Results: One hundred thirty four out of 330 samples (40.7\%) were positive for at least 1 of the tested viruses. Adenovirus was detected with a frequency of $29.9 \%$, followed by Rhinovirus (23.1\%), Influenza virus (21.6\%), RSV and Parainfluenza viruses (12.7\% each) and Enterovirus (9\%). Adenovirus was more frequent in spring, summer and winter (35\%, 22\%, and $36.7 \%$, respectively) and Rhinovirus was common in winter (26.7\%), followed by spring and autumn (25\% each). Frequency of Influenza virus was $22.5 \%$ in spring, $15.6 \%$ in summer, $21.9 \%$ in autumn and $26.7 \%$ in winter. The rates of $R S V$ were $9.4 \%, 15.6 \%, 12.5 \%$ and $13.3 \%$, from spring to winter. Enterovirus was isolated in $7.5 \%$ samples in spring, rising to $15.6 \%$ in summer, falling to $9.4 \%$ and then to $3.3 \%$ in cold seasons. Parainfluenza was found $2.5 \%$ in spring, $21.9 \%$ in summer, $18.8 \%$ in the fall and $10 \%$ in winter.

Conclusions: Adenoviruses are the most commonly detected viruses in childhood URTI. Although frequency of different viruses varies according to the seasons of year, this difference is not significant.
\end{abstract}

Published by Kowsar Corp, 2013. cc 3.0.

Implication for health policy/practice/research/medical education:

This Paper Describes Variations in The Viral Etiology of URTI in Children Useful to Deciding Management Options.

\footnotetext{
* Corresponding author: Abdollah Karimi, Pediatric Infections Research Center, Department of Pediatric Infectious Diseases, Mofid Children Hospital, Shahid Beheshti University of Medical Sciences, Dr. Shariati Ave, Tehran, IR Iran. Tel/ Fax:+98-22226941, E-mail: pediatric_center@yahoo.com

DOI:10.5812/pedinfect.5199

(C) 2013 Pediatric Infections Research Center and Shahid Beheshti University of Medical Sciences; Published by Kowsar Corp.

This is an open access article distributed under the terms of the Creative Commons Attribution License(http://creativecommons.org/licenses/by/3.0), which permits unrestricted use, distribution, and reproduction in any medium, provided the original work is properly cited.
} 
- Please cite this paper as:

Gorjipour H, Karimi A, Fahimzad A, Shiva F, Fallah F, Shamshiri A. Seasonal Frequency of Viruses Associated With Upper Respiratory Tract Infections in Children.Arch Pediatric Infect Dis.2013;1(1): 9-13. DOI: 10.5812/pedinfect.5199

\section{Background}

Upper respiratory tract infections (URTI) in children are the most frequent reasons for visiting a family doctor, commonly resulting in inappropriate prescription of antibiotics (1-3). In underdeveloped countries, a viral respiratory tract infection may be followed by serious complications (1). More than 200 viral species are associated with respiratory tract diseases in human and this number is increasing. The relationship between clinical manifestations and causal microorganisms has been reported by various authors but viral detection would provide definite data about the relationship between the clinical picture and specific causative agents (4-6). Specific viral diagnosis may help decrease the use of unnecessary antibiotics (3). Recent studies have shown that some pediatric patients with acute respiratory tract infection become infected simultaneously with multiple respiratory viruses $(4,7,8)$. Rhinovirus, Parainfluenza virus, Respiratory Syncytial virus (RSV), and coronavirus play an important role in URTI $(1,2)$. Since the pattern of causative organisms for respiratory tract infections may vary in different geographical locations, it is important to determine the epidemiology of URTI in a community, in order to plan a rational approach for managing all these very common illnesses in children.

There are few reports from developing countries addressing the issue of viral causes of URTI in all 4 seasons of the year. Previous studies have dealt with specific age groups, hospitalized children, and the infections of the lower respiratory tract $(4,6,9)$.

\section{Objectives}

This study was carried out with the objectives of determining the role of 6 different viruses, namely Rhinovirus, Influenza virus, Parainfluenza virus, RSV, Adenovirus and Enterovirus in causing upper respiratory tract infection in children during various seasons of year and 2- month to 12 -year-old age groups.

\section{Patients and Methods}

Children between the ages of 2- month and 12 -year-old with clinical signs and symptoms of URTI referring to the outpatient clinics of Mofid Children's Hospital in Tehran, Iran, from October 2009 to September 2010, were selected for this cross-sectional study during the one -year period of study. We continued carefully the study for 1 whole year so that patients could be evaluated during all the 4 seasons. We selected children consecutively in order to meet our inclusion criteria during each season, until the required number for each season was reached.

Inclusion criteria: Children with at least 2 of the following clinical manifestations of URTI i.e. rhinorrhea, sneezing, sore throat, or cough lasting for $<7$ days, with or without fever. Exclusion criteria: the Presence of any of the following signs: tachypnea, chest wall retraction, nasal flaring, asthma, allergy, or an underlying disease involving the cardio-pulmonary system.

After obtaining approval from the ethical committee of the Pediatric Infections Research Center and parental consent, all children were examined by the members of the study team, (pediatricians or pediatric residents) and all relevant findings were documented on a pre-designed questionnaire. Nasopharyngeal swabs were taken from the patients of the study and sent to the laboratory in VTM transitional median ice bags where they were stored at $70^{\circ} \mathrm{C}$ and the different viruses were identified by the PCR method (10).

The used primers for identifying the viruses were as follows:

Influenza/Forward: 5-CAGAGACTTGAAGATGTC-3

Influenza/reverse: 5-CGATCAAGAATCCACAATAAGTGCAAGATCCCAATAATA-3

RSV|Forward: 5-GGAACAAGTTGTTGAGGTTTATGAATATGC-3 RSV/reverse: 5-CTTGACTTTGSTAAGAGCCATTCT-3 Adenovirus/Forward: 5-CCCTGGTA(GT)CC(AG)AT(AG)TTGTA-3 Adenovirus/Reverse: 5 GACTC (ct) TC(AT)GT(GC)AG(CT)GGCC-3 Rhinovirus/Forward:5-GCACTTCTGTTTCCCC-3

Rhinovirus/Reverse: 5-CGGACACCCAAAGTAG-3

Parainfluenza/Forward:5-CTTTGGGAGTTGAACAAACAGTT-3 Parainfluenza/Reverse: 5-CTCGAGGTTGTCAGGATATAG-3 Enterovirus/Forward: 5-CATGGTGAGAAGAGTCTATTGAGCTA-3 Enterovirus/Reverse: 5-GGACACCCAAAGTAGTCGGTTC-3

Frequency of each virus for URTI in children was presumed to be $5 \%$ and the sample size was determined to be 292 patients.

Statistical analysis was done by SPSS software, and the frequency of different viruses in different age groups, seasons and both genders was determined.

\section{Results}

A total of 330 children with acute URTI (61.2\% males) were included, 80 patients in the fall, 90 in winter, 80 in spring and 80 in summer. One-hundred and thirty-four samples were positive for at least 1 of the tested viruses. $63(47 \%)$ of these patients were $2>$ years old, $48(35.8 \%)$ between $2-5$ years old and $23(17.2 \%)$ were $>5$ years old. Clinical manifestations of the respiratory infection in children with a detectable viral pathogen were as follows: 
$96.9 \%$ of the patients had coryza, $84.0 \%$ cough, $71.6 \%$ fever and $17.2 \%$ sore throat.

Frequency of different viruses detected in the 134 positive samples was as follows:

Adenovirus 30\%, Rhinovirus 23\%, Influenza virus 22\%, Respiratorysyncytial virus $13 \%$, Para influenza virus $13 \%$ and Entero virus $9.0 \%$ (Figure 1).

Adenovirus was the most commonly isolated pathogen in infants and toddlers, Rhinovirus and Influenza virus were more frequent in children aged $5<$ years, (Table 1). More than 1 virus were detected in 12 specimens, 3 of these had been collected from children $<2$ years old, 7 from preschoolers between 2-5 years of age and 2 samples from school children $>5$ years old (Table 1 ).

As depicted in Table 2, fever was commonly present in most infections except for Enterovirus, while sore throat was a predominant symptom in infections with Influenza virus and Rhinoviruses.
Frequency of different pathogens during different seasons is shown in Figure 2.

\section{Discussion}

In our study, with a population of 330 children with URTI, specific etiologic agents were identified in 134 (40.7\%) patients. The identification frequency of etiological agents in children with acute respiratory infections varies widely with geographical location and viral isolation techniques. Lin's study from Taiwan quoted a figure of $40 \%$ and in children hospitalized with ARI in Korea, a specific viral agent was identified in $25 \%$ of nasopharyngeal aspirates rates $(5,6)$. Authors from Western India reported the detection of a viral antigen in $37.1 \%$ of 385 children with respiratory tract infections (11). In a study on young Finnish children under the age of 4 years with acute symptoms of URTI lasting for $<48$ hours, a viral etiological

\begin{tabular}{|c|c|c|c|c|c|c|}
\hline \multirow[t]{2}{*}{ Virus Type } & \multicolumn{2}{|c|}{$<2 y(n=63)$} & \multicolumn{2}{|c|}{$2-5 y(n=48)$} & \multicolumn{2}{|c|}{$>5 y(n=23)$} \\
\hline & No. & $\%$ & No. & $\%$ & No. & $\%$ \\
\hline Influenza virus & 9 & 14.3 & 14 & 29.4 & 6 & 26.1 \\
\hline Parainfluenza virus & 7 & 11.1 & 7 & 14.6 & 3 & 13 \\
\hline Adenovirus & 22 & 34.9 & 15 & 31.3 & 3 & 13 \\
\hline Rhinovirus & 11 & 17.5 & 14 & 29.2 & 6 & 26.1 \\
\hline$R S V$ & 7 & 11.1 & 5 & 10.4 & 5 & 21.7 \\
\hline Enterovirus & 10 & 15.9 & 0 & & 2 & 8.7 \\
\hline Total virus types detected & 66 & & 55 & & 25 & \\
\hline
\end{tabular}

Abbreviation: RSV; respiratory syncytial virus

\begin{tabular}{|c|c|c|c|c|}
\hline \multirow[b]{2}{*}{ Viruses } & \multicolumn{4}{|c|}{ Manifestations, \% } \\
\hline & Cough & Coryza & Fever & Sore Throat \\
\hline Influenza virus & 22.1 & 21.3 & 20.8 & 30.4 \\
\hline Para influenza virus & 12.4 & 11.8 & 14.6 & 21.7 \\
\hline Adenovirus & 31 & 29.9 & 31.3 & 17.8 \\
\hline Rhinovirus & 22.1 & 22.8 & 22.9 & 30.4 \\
\hline RSV & 13.3 & 12.6 & 10.4 & 17.4 \\
\hline Enterovirus & 8 & 9.4 & 9.4 & 0.0 \\
\hline
\end{tabular}

Abbreviation: RSV; respiratory syncytial virus

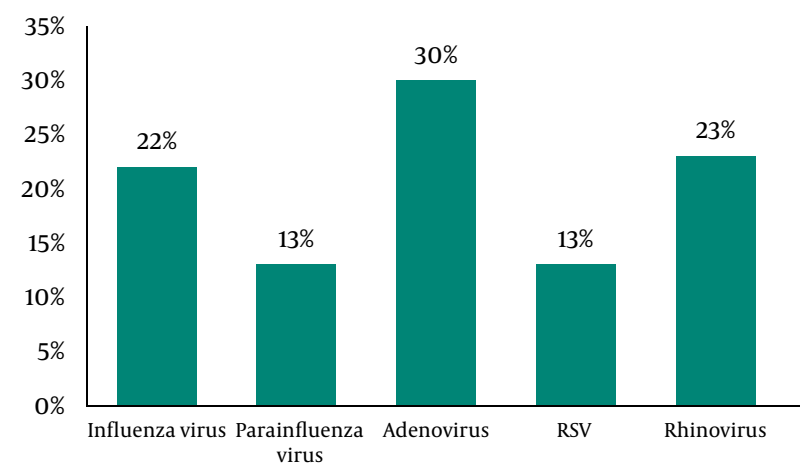

$\overline{\text { Figure 1. Frequency of Different Viruses Detected in Nasopharyngeal }}$ Swabs of Children With URTI in 2009-2010 agent was discovered in $92 \%$ (7). In other study on young adults, the virus detection rate for acute respiratory infections was almost 70\% (12). However, a study that tested for the presence of Adenovirus, Influenza virus and RSV by rapid chromatography detected one of the three viruses in $16 \%$ of throat swabs in children aged between 3 months and 15years with URTI referring to the outpatient clinics of a children's hospital affiliated to Shahid Beheshti University of Medical Sciences in Tehran (13).

Although our viral detection rate was higher than some of the studies from South East Asia, it was considerably lower than the Finnish study; this could be due to the fact that we did not test for the presence of corona virus 


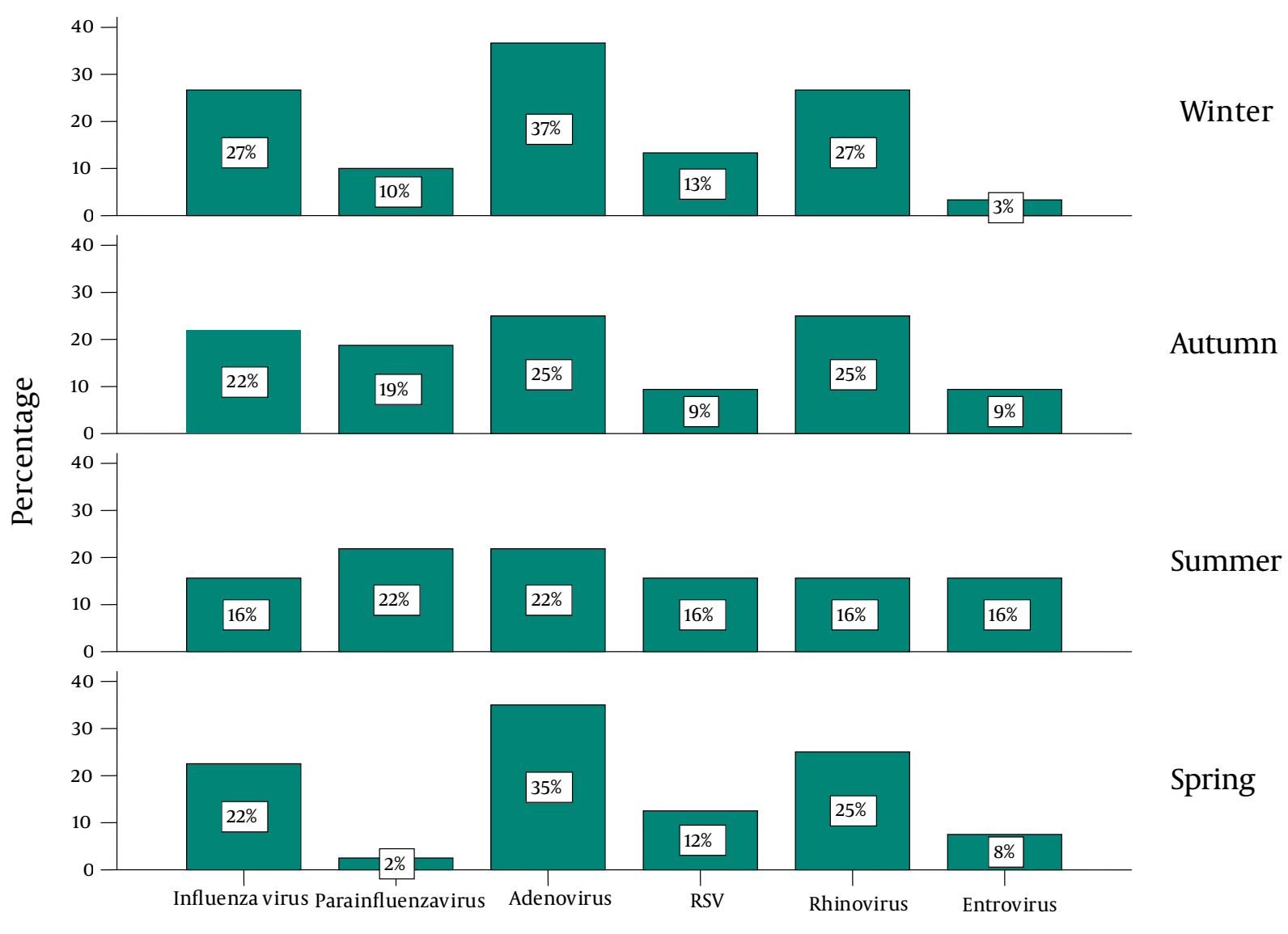

Figure 2. Frequency of Different Pathogens During Different Seasons of the Year

which has been reported as a common cause of mild URTI in children in various studies $(1,2,7)$. In our study, most frequent causes of URTI were Adenovirus (30\%), Rhino virus (23\%), and Influenza virus (22\%). In Rouhola's study Rhino virus was found to be the most common agent detected in $71 \%$ of children, while Adenovirus was only found in $12 \%$ and Enterovirus in 10\% (7). In a study performed in Iran, Adenovirus was the most common pathogen causing URTI among subjects (13).

As we had expected, we found that the frequency of Adenovirus was $36.7 \%$ in winter and entero viral infection was the most common in summer and the least common in winter. The seasonality of respiratory viruses has been reported in other studies as well, especially in temperate climates; Influenza and RSV were more prevalent in winter and Rhinoviruses in spring and the fall (14). In Barati's study, Influenza virus was more commonly isolated in winter and RSV in spring and the fall, but Adenovirus did not follow a specific seasonal pattern (13). In addition, no seasonal variation was found in the prevalence of Adenovirus in children with acute respiratory infection in Taiwan (5). Some authors from the tropical regions have reported a higher prevalence of RSV infection in rainy seasons (15).
RSV was the third common viral pathogen in children aged $>5$ years after Influenza virus and Rhinovirus in our study. Most viral pathogens (47\%) were detected in young children $<2$ years and the most common virus was Adenovirus, detected in $34.9 \%$ of cases. In our study, Entero virus was not isolated in 2-5-year-old ones with URTI. The unexpected low rate of RSV in our patients with lower ages can be explained by the fact that our samples were collected from the outpatient clinics as young children with RSV infection got very ill, they usually needed to be admitted to hospitals $(11,14,15)$. RSV was isolated from $73 \%$ of 178 young children $<5$ years old admitted with acute respiratory infection in Sao Paulo, Brazil and from the majority of hospitalized young children in India but only $13 \%$ of their OPD patients $(11,16)$. In some studies, RSV was the most common pathogen detected from the respiratory tract of children with respiratory tract infections, but in Lin's study, RSV was the least common organism found in URTIs in children $(5,6,17,18)$.

Infections with $1<$ virus were detected in 12 of our subjects; only three of these were $2>$ years. Concomitant presence of multiple viruses was noted in Rouhola's study as well.In26\% of their under study subjects, 2 viruses were detected while 
in $6 \%, 3$ or 4 viruses were isolated from the nasopharyngeal aspirates (7). Co-infection with multiple viral agents has also been reported in children hospitalized with lower respiratory tract infections in China; similar to our study in which a higher frequency of simultaneous infection with two viruses was noticed in the 2-5 year age group (4), the highest prevalence of co-infection with two or more viruses was in the3-6 year age group (4). The reason might be higher possibility of contact with other children in day-care centers and other places.

The results of this study demonstrate that Adenovirus and Rhinovirus were the two most common viruses isolated from pediatric outpatients with acute URTIs; Adenovirus was more frequent in spring and winter and coryza and cough were the most common symptoms. On the whole, the percentage of boys with viral URTI was higher than girls, but in this study Adenovirus infection was more common in females.

Findings of this study delineate the epidemiology of upper respiratory tract infections in children during different seasons of year and help plan strategies for prevention from and treatment of URTIs and make health personnel aware of the ineffectiveness of antibiotics in the management of URTIs.

\section{Acknowledgments}

We thank the patients and their physicians, Drs. R. Faramarzi, Hashemi, and Sakhavi for their participation in this study. We are also grateful to the staff of the Pediatric Infections Research Center for making this research possible. Our special thanks are due to Dr. M. Navidinia and Mrs. Gholizadeh for their excellent technical assistance.

\section{Authors' Contribution}

None declared.

\section{Financial Disclosure}

None declared.

\section{Funding/Support}

None declared.

\section{References}

1. Nokso-Koivisto J. Viral upper respiratory tract infections in young children. Citeseer; 2004 [updated 2004; cited];1-70]. Available from: http://citeseerx.ist.psu.edu/viewdoc/download?doi=1 0.1.1.133.6997\&rep $=$ rep1\&type $=$ pdf.

2. Cherry JD. The common cold In. In: Feigin RD, Cherry JD, Demmler GJ, Kaplan SL, editors. Text book of pediatric Infectious Diseases. 5th ed. United States of America: Saunders; 2004. p. 140-7.

3. Byington CL, Castillo H, Gerber K, Daly JA, Brimley LA, Adams S, et al. The effect of rapid respiratory viral diagnostic testing on antibiotic use in a children's hospital. Arch Pediatr Adolesc Med. 2002;156(12):1230-4

4. Peng D, Zhao D, Liu J, Wang X, Yang K, Xicheng H, et al. Multipathogen infections in hospitalized children with acute respiratory infections. Virol J. 2009;6:155.

5. Lin TY, Huang YC, Ning HC, Tsao KC. Surveillance of respiratory viral infections among pediatric outpatients in northern Taiwan. J Clin Virol. 2004;30(1):81-5.

6. Kim MR, Lee HR, Lee GM. Epidemiology of acute viral respiratory tract infections in Korean children. J Infect. 2000;41(2):152-8.

7. Ruohola A, Waris M, Allander T, Ziegler T, Heikkinen T, Ruuskanen O. Viral etiology of common cold in children, Finland. Emerg Infect Dis. 2009;15(2):344-6.

8. Calvo C, Garcia-Garcia ML, Blanco C, Vazquez MC, Frias ME, PerezBrena $\mathrm{P}$, et al. Multiple simultaneous viral infections in infants with acute respiratory tract infections in Spain. I Clin Virol. 2008;42(3):268-72.

9. Fabbiani M,Terrosi C, Martorelli B,Valentini M, Bernini L, Cellesi C, et al. Epidemiological and clinical study of viral respiratory tract infections in children from Italy. J Med Virol. 2009;81(4):750-6.

10. Freymuth F, Vabret A, Galateau-Salle F, Ferey J, Eugene G, Petitjean J, et al. Detection of respiratory syncytial virus, parainfluenzavirus 3, adenovirus and rhinovirus sequences in respiratory tract of infants by polymerase chain reaction and hybridization. Clin Diagn Virol. 1997;8(1):31-40.

11. Yeolekar LR, Damle RG, Kamat AN, Khude MR, Simha V, Pandit AN Respiratory viruses in acute respiratory tract infections in Western India. Indian J Pediatr. 2008;75(4):341-5.

12. Makela MJ, Puhakka T, Ruuskanen O, Leinonen M, Saikku P, Kimpimaki M, et al. Viruses and bacteria in the etiology of the common cold. JClin Microbiol. 1998;36(2):539-42.

13. Barati M, Noorbakhsh S, Tabatabaei A, Ebrahimi TF, Talebi-Taher M. Adenovirus, Influenza virus A, B and Respiratory syncytial virus infection in children. Int J Inf Dis. 2008;12(1):66.

14. Monto AS. Occurrence of respiratory virus: time, place and person. Pediatr Infect Dis J. 2004;23(1 Suppl):S58-64.

15. Sarma JB, Ahmed GU. Characterisation of methicillin resistant $S$. aureus strains and risk factors for acquisition in a teaching hospital in northeast India. Indian J Med Microbiol. 2010;28(2):127-9.

16. Pecchini R, Berezin EN, Felicio MC, Passos SD, Souza MC, Lima LR, et al. Incidence and clinical characteristics of the infection by the respiratory syncytial virus in children admitted in Santa Casa de Sao Paulo Hospital. Braz J Infect Dis. 2008;12(6):476-9.

17. Mlinaric-Galinovic G, Ugrcic I, Detic D, Bozikov J. Epidemiological picture of respiratory viral infections in Croatia. Acta Med Iugosl. 1991;45(3):203-11.

18. Ahn KM, Chung SH, Chung EH, Koh YJ, Nam SY, Kim JH, et al. Clinical characteristics of acute viral lower respiratory tract infections in hospitalized children in Seoul, 1996-1998. J Korean Med Sci.1999;14(4):405-11. 